earlier had not been made available or for other reasons. Clearly this is a highly unsatisfactory state of affairs-several of the colours for which no A.D.I.s were given are still being used in food.

Some addition of chemicals to food to preserve it and to enable it to be distributed in suitable processed forms is unavoidable. But only a fine line separates the use of chemicals for these reasons and the unnecessary adulteration of food for no reason other than profit. Laboratory tests and regulatory committees go a long way to ensuring that we come to no harm from chemicals added to food, but no system of safeguards merits absolute confidence, and if we mind our bellies very studiously and very carefully we will eschew all unnecessary adulteration of food. We can make a start by eliminating synthetic food colours.

1 General Principles Governing the Use of Food Additives-First Report. W.H.O. Technical Report Series, No. 129, 1957.

${ }^{2}$ Evaluation of Certain Food Additives: 18th Report of Joint F.A.O./W.H.O. Expert Committee on Food Additives. W.H.O. Technical Report Series Expert Committee
No. $557,1974$.

\section{Home Therapy for Haemophilia}

More than $90 \%$ of the haemorrhages suffered by severely affected haemophiliacs affect their joints and muscles. These haemorrhages may occur at intervals of a month or so-in some cases several times a week-and in addition to causing extreme pain and distress at the time of bleeding can eventually lead to severe joint and muscle damage and permanent crippling. Furthermore, the frequent journeys to and from hospital for treatment result in repeated disruption of the liferoutine of both the patient and his family.

If antihaemophilic factor is given by intravenous injection as soon as possible after the onset of bleeding it rapidly controls haemorrhage and relieves pain; this striking effect has led to the introduction of home therapy for haemophilia. ${ }^{1-5}$ So far, the administration of antihaemophilic factor at home is proving to be both feasible and remarkably free from problems. In their recent study of 45 patients on home therapy, Levine and Britten ${ }^{4}$ found no morbidity attributable to the treatment, and the only important hazard reported was the exposure of family members to hepatitis from contaminated needles: one such case occurred in their group.

The purpose of home therapy is to try to minimize the effects of joint and muscle haemorrhages on the patient's daily work and activities and to reduce the incidence of long-term crippling. Patients are told, however, that if a haemorrhage is large or dangerous, particularly into a site such as the abdomen or neck; or if it comes from a large wound; or if headache develops especially after head injury, they should telephone their haemophilia centre as soon as possible and seek advice. Usually in such cases the patient will be asked to go to his centre, having first received a dose at home to protect him from the effects of the journey.

The criteria for putting a patient on home therapy vary slightly from centre to centre, but at present it is generally agreed that he should be severely affected, should not have antibodies to factor VIII, should have good veins, and should have a competent relative who can give the transfusions if the patient is not to transfuse himself. In an older patient with difficult veins it may be justified, though rarely, to establish an arteriovenous fistula at the wrist in order to have a readily accessible vascular channel and so allow the patient the benefits of home therapy. Sussman and Lozman ${ }^{6}$ have recently described such a procedure in one of their patients; after the operation the patient was able to carry out his own intravenous therapy at home without complications.

Freeze-dried antihaemophilic factor is the material of choice for home treatment, ${ }^{7}$ since it is stable on storage, easily reconstituted, and rarely causes reactions. Its potency is such that an effective dose can be given in small volumes, making it possible to give the dose by injection with a syringe. Unfortunately, freeze-dried antihaemophilic factor produced by the N.H.S. is still in short supply, and as a result some centres are being forced to use cryoprecipitate, which is not an ideal material for home therapy, whilst others have to buy antihaemophilic factor from commercial sources. The commercial preparations available in Britain are very good but expensiveat $10-12 p$ per unit of factor VIII a single dose for a small haemarthrosis may cost $£ 25-30$.

The cost of embarking on large-scale home-therapy programmes is understandably causing some concern, especially since it is not yet clear whether home therapy will lead to an increase or a decrease in usage of antihaemophilic factor. Rabiner and Telfer ${ }^{1}$ have reported an increased consumption by patients going on home therapy, but Levine and Britten ${ }^{4}$ and Le Quesne and her colleagues ${ }^{5}$ found no evidence of increased use in their patients. Furthermore even if experience shows that home therapy results in an increase in consumption of antihaemophilic factor, it may very reasonably be argued that the patients had been inadequately treated before starting home therapy and that such an increase would be justified. In addition, the benefits of home therapy are not limited only to the patient; the beneficial effect on the family of removing anxiety, tension, and frustration is very striking and is a welcome bonus.

1 Rabiner, S. F., and Telfer, M. C., New England fournal of Medicine, 1970, 283, 1011 .

2 Rabiner, S. F., Telfer, M. E., and Fajardo, R., fournal of the American Medical Association, 1972, 221, 885 .

3 Bellingham, A., et al., British Medical fournal, 1967, 4, 531.

4 Levine, P. H., and Britten, A. F. H., Annals of Internal Medicine, 1973, $78,195$.

5 Le Quesne, Barbara, et al., Lancet, 1974, 2, 507.

Sussman, L. N., and Lozman, H., Fournal of the American Medical Association, 1974, 230, 437.

${ }^{7}$ Medical Research Council's Blood Transfusion Research Committee Working Party, British fournal of Haematology, 1974, 27, 391.

\section{Megacolon}

Megacolon may be defined as a state in which the bowel is persistently dilated and often thick-walled, and is associated with long-standing constipation. Constipation, in this context, implies infrequent and incomplete passage of faeces per rectum.

Patients with megacolon can be broadly divided into two main groups according to whether or not ganglia are present in the intermuscular plane of the rectal wall. Their complete absence, even along a short segment of rectum, denotes Hirschsprung's disease. If ganglia are present the megacolon may be secondary to some predisposing factor such as a stricture, a congenital anorectal abnormality, Chagas's disease, or a corda equina lesion; or there may be no obvious organic reason why the bowel should be so dilated. This latter group is often termed "idiopathic" and it accounted for $60 \%$ 
of 100 consecutive patients attending the Johns Hopkins Hospital with megacolon over a ten year period. ${ }^{1}$

The most difficult clinical problem is to differentiate between those patients with Hirschsprung's disease and those with idiopathic megacolon. An early onset of constipation, abdominal distension, visible peristalsis and poor general health, together with the finding of a normal sphincter and empty rectum, are highly suggestive of Hirschsprung's disease. In contrast, a later onset of constipation, the presence of a personality disorder, faecal soiling, and the finding of a lax sphincter with a loaded rectum are prominent features suggestive of idiopathic megacolon. A barium enema may show coning above a narrow segment or dilatation down to the anorectal ring, especially on a lateral view. Anorectal manometry is $100 \%$ accurate in establishing whether the internal sphincter relaxes on rectal distension, and a full thickness rectal biopsy, taken from the appropriate place, will show whether ganglia or abnormal nerve trunks are present.

The management of Hirschsprung's disease is surgical and depends on age at presentation. In neonates an immediate colostomy is a wise precaution against the risk of enterocolitis, which has a $25 \%$ mortality. After six months of age a definitive procedure should be undertaken to overcome the obstructive segment. The management of idiopathic megacolon is conservative in the first instance. The colon should be emptied and kept empty by means of laxatives, enemata, or suppositories, often in combination. Retraining may take a long time; frequent clinic attendances encourage the patient to continue with the regimen and overcome what may seem an intractable problem. The results of surgical intervention are disappointing.

Better understanding of the pathogenesis of megacolon, and especially Hirschsprung's disease, was made possible by histochemical techniques which distinguished nerves containing acetylcholinesterase ( $\mathrm{AChE}$ ) from adrenergic nerves in the bowel wall. ${ }^{2} 3$ The thick, unmyelinated nerve bundles from the mural plexus of the aganglionic segment in Hirschsprung's disease were found to be strongly $\mathrm{AChE}$ positive, suggesting that they at least emanated from the parasympathetic system. In normal patients adrenergic nerves were seen to be in close relationship with the intramural ganglia, on which they presumably exert an inhibitory action in the normal rectum, but in the absence of ganglia these nerves are variably distributed in increased numbers throughout the muscle layers. Smith ${ }^{4}$ examined sections of the intramural plexus cut parallel to the gut wall from patients with Hirschsprung's disease and showed that not only was there a diminution of the ganglion cell population but also that there were considerable nerve abnormalities in the dilated bowel some distance above the aganglionic segment. It was suggested that the megacolon was part of the primary disorder and not merely secondary to the distal obstruction. ${ }^{4}$ Garrett, Howard, and Nixon ${ }^{5}$ further showed that there was a considerable variation in the number of $\mathrm{AChE}$-positive nerves distributed to the circular muscle in the aganglionic bowel. In general there were many more than normal, and they were able to find a distinct correlation between the number of such nerves and the severity of the disease. The junctional zone between normal and aganglionic bowel contained some ganglia but was relatively deficient in muscular nerves. Those patients with the most AChE-positive nerves presented with severe neonatal obstruction, whereas those patients with fewest fibres presented with simple constipation and even failed to show a constricted segment on barium enema examination. Garret et al. ${ }^{5}$ suggested that this would explain why patients with the same length of aganglionosis may present either in early infancy or later in adult life. They concluded that aganglionosis results in a failure of co-ordinated contraction and inhibition and that the cholinergic muscular nerves are probably responsible for the typically contracted state of the distal bowel. A sparsity of ganglia and the diminished numbers of muscular nerves in the junctional zone result in a weak propulsive effort which not only aggravates the obstruction but also leads to progressive dilatation.

Patients with megacolon of unknown aetiology may represent a less severe form of abnormality, in which the rectum and colon have fewer ganglia than normal and sparse muscular innervation, similar to the junctional zone seen above the aganglionic segment in Hirschsprung's disease. This view is supported by work in progress by Smith, who examined the resected colons from five patients with idiopathic megacolon and found a degree of hypoganglionosis in all of them. ${ }^{6}$ Further studies may show whether this abnormality is present in other similar patients.

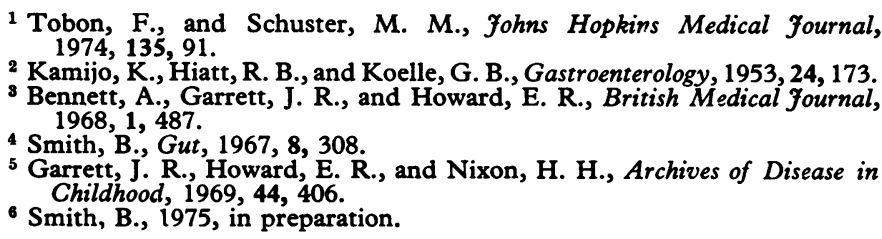

\section{Waiting Game?}

Hospital waiting lists are lengthening day by day. Meanwhile Mrs. Castle seems intent on playing a waiting game with N.H.S. consultants. Perhaps she is bereft of any strategy or is the prisoner of militants in her own party. Whatever the cause the outcome of the confidential "talks about talks" (25 January, p. 174) is disappointing, saying little that was not already known about the Government's views. Not surprisingly the professions' representatives remain unimpressed by her promisory note. (p. 468).

Mrs. Castle's statement in Parliament on 17 February (p. 465) added little in bringing a constructive solution to the two-month contract dispute any nearer. Does she hope that soothing ministerial words implying support for a substantial pay award in April will persuade consultants back to their unlimited commitments? With the Chancellor of the Exchequer forecasting national bankruptcy if others follow the miners through their breach in the social contract doctors may well be sceptical about their own financial prospects this year.

Consultants want their contracts revised urgently. The outcome of the forthcoming review might then be rewards that reflect more fairly than now work done, including on-call responsibilities. This would provide a sounder foundation to the substantial pay increases that consultants deserve than a straight percentage rise on current salaries. The Government's behaviour has now made it unlikely that short-term revision of the present contract can be agreed in time. Furthermore, it has lessened the chances of an early start on the more difficult task of negotiating long-term reform of the contracts.

As we went to press the Central Committee for Hospital Medical Services was due to hold a special meeting on 20 February. Before relaxing sanctions or agreeing to resume formal negotiations its members-and the H.C.S.A.-will want from Mrs. Castle a better letter of intent than she has so far written. 